I have come to a different view, which I think represents the facts more adequately than these others. I agree with Piccard in thinking that the parent substance of the actinium series is an isotope of uranium, of atomic weight 240 , not genetically connected with it; but differ principally in thinking the atomic weight of actinium is not 232 , and that uranium $\mathrm{Y}$ is not the immediate parent of protoactinium.

The scheme is as follows :

\begin{tabular}{|c|c|c|c|c|}
\hline Element. & Period. & $\begin{array}{l}\text { Atomic } \\
\text { Number. }\end{array}$ & Radiation. & $\begin{array}{l}\text { Atomic } \\
\text { Weight. }\end{array}$ \\
\hline Actino-uranium I . & $>5 \times 10^{9}$ years & 92 & $\alpha$ & 240 \\
\hline Uranium $\mathrm{Y}_{1}$. & 25.5 hours & 90 & $\beta$ & 236 \\
\hline Uranium $\mathrm{Y}_{2}^{1}$ & $\begin{array}{c}\text { Probably very } \\
\text { short }\end{array}$ & 91. & $\beta$ & 236 \\
\hline Actino-uranium II . & $>2 \times 10^{6}$ years & 92 & a & 236 \\
\hline $\begin{array}{l}\text { Parent of proto- } \\
\text { actinium }\end{array}$ & $>00$ year: & 90 & & \\
\hline Proto-actinium & $<1.2 \times 10^{4}$ years & $\begin{array}{l}90 \\
91\end{array}$ & $\begin{array}{l}\beta \\
\alpha\end{array}$ & $\begin{array}{l}232 \\
232\end{array}$ \\
\hline Actinium . & 20 years & 89 & $B$ & 228 \\
\hline Radio-actinium, etc. & $19 \cdot 5$ days & 90 & $a$ & 228 \\
\hline
\end{tabular}

This scheme was arrived at from a consideration of the periods of corresponding members of the three disintegration series. Successive radio-active transformations may be classed in three ways :

(I) Four $a$-particles (five in the uranium series) follow each other without the expulsion of a $\beta$-particle

(2) An $a$-particle is followed by two $\beta$-particles in succession and then an $a$-particle.

(3) An $a$-particle is followed successively by a $\beta$-, an $\alpha$-, and a $\beta$-particle.

In the three known examples of the first type each product has on the average 800 times the period of its successor. (For the uranium series the ratio is 766 , for the thorium 764 , for the actinium 918.) Yet the periods of average corresponding members of the three series (in the order given) are in the proportion of $5 \times \mathrm{IO}^{5}, 50$, and $\mathrm{I}$. Now the difference in atomic weight between the uranium and the thorium series is 2 only. I have assumed that if a time ratio of $5 \times 10^{5}$ to 50 corresponds to 2 , a ratio of 50 to $I$ corresponds to so small a fraction as to be negligible. If this be justifiable the atomic weights of the thorium and actinium series become identical. It follows that actinium has an atomic weight of 228 and so cannot be genetically connected with uranium if $\alpha$ and $\beta$ - be the only particles expelled in radio-active transformations.

I have found interesting relations connecting the periods of the bodies of the second and third types of successive transformations, but the only thing necessary for the scheme to be deduced is that in both these types the period of the first $\beta$-particle is greater than that of the second. There are in all, excluding the change, parent of $\mathrm{Pa} \longrightarrow \mathrm{Pa} \rightarrow \mathrm{Ac} \rightarrow \mathrm{RdAc}$, ten examples of the second and third types known, in all of which this relation holds. It is consequently not unreasonable to suppose that the parent of proto-actinium has a longer period than actinium and consequently cannot be uranium Y. As the latter is very probably genetically connected with actinium, and is undoubtedly a product of a body of atomic number 92, it must be an isotope of the parent of proto-actinium probably with an atomic weight 4 units greater. To connect it with the parent of proto-actinium it is simplest to suppose that it is followed by a quick-changing product uranium $Y_{2}$, corresponding to uranium $\mathrm{X}_{2}$, which is the parent of an isotope of the original actinouranium, and this immediately precedes the parent of actinium as shown in the table above.
The scheme, so far as I am aware, does not seriously contravene the results of experimental work, and appears to be nearer what one would expect by analogies from the thorium and uranium series and the lower part of the actinium series than those previously proposed. None of the new proposed data given in the table contravene the Geiger-Nuttall relation. Moreover, they appear to make Fajan's rules connecting the order of the atomic weights of isotopic a-ray and $\beta$-ray bodies with the order of their periods more nearly exact than hitherto they have appeared to be. To Fajan's a-ray rule there have been hitherto three exceptions; on the new scheme there is only one. The two exceptions to his $\beta$-ray rule do not exist in the new scheme.

Our experimental work on the relative activity of uranium and its products in pitchblende leads to a ratio in the amounts of actinio-uranium and uranium $I$ in uranium of about 5 to 95 . But the experimental results to be expected on the assumption that uranium II breaks up dually in this proportion to form the actinium and radium series lead to so similar a result that at present our experimental work is insufficiently advanced to lead to a decision.

Mr. W. G. Guy in this laboratory has been for some time engaged with me in repeating Dr. O. Hahn's work on uranium $Z$ as described in the latter's publication of I92I, and has independently come to very similar results to those described in Hahn's second and recent paper. He confirms Hahn's important result that uranium $\mathrm{X}_{1}$ breaks up dually, in both cases with the emission of a $\beta$-particle to form uranium $\mathrm{X}_{2}$ and uranium $\mathrm{Z}$ in a ratio of about 997 to 3. $\mathrm{He}$ has also measured the periods of uranium $\mathrm{Y}$, uranium $\mathrm{Z}$, and uranium $\mathrm{X}_{2}$ accurately, and finds them to be 25.5 hours, 6.69 hours, and 70.5 seconds respectively. These agree with the published values. Dr. Hahn does not appear to have noticed that the branching ratio, which he gives as 996.5 to 3.5 , is approximately equal to the reciprocal of the periods of the two bodies formed. This agreement may be a coincidence. If it is not, it would not be difficult to deduce from it information which might throw light on the mechanism of disintegration.

Dr. Lee's Laboratory, Christ Church, A. S. Russeli. Oxford, May 3.

\section{Slag mistaken for a Meteorite at Quetta.}

WIDE publicity has been given in the Press to a story of a fall of a large meteoric mass in Quetta, Baluchistan Agency.

The Geological Survey of India has always paid particular attention to falls of this kind, and, within an hour of the receipt of the news in Calcutta, was in telegraphic communication with the authorities in Quetta, and the receipt of specimens was anxiously awaited. Ultimately, approximately two hundredweights of material were carefully examined, and found to be entirely a glassy slag in which were embedded bits of iron wire and thin iron bands.

So far as can be judged, the sequence of events was as follows: A large stack of baled bhoosa (chopped straw) of about five hundred tons weight was fired by a flash of lightning during a heavy thunderstorm, and a mass of slag some five tons in weight was left behind. A bystander suggested that this mass was of meteoric origin.

G. H. TIPPER.

Geological Survey of India, Calcutta, March II.

NO. 2795 , VOL. I I I] 